\title{
The metabolic syndrome in Spanish migrants to Brazil: Unexpected results
}

\author{
Judith M.D.C. Pousada ${ }^{a}{ }^{*}$, Maria M.S. Britto ${ }^{a}$, Thomaz Cruz ${ }^{a}$, \\ Maria de Lourdes Lima ${ }^{b}$, Ines Lessa ${ }^{c}$, Denise C. Lemaire ${ }^{d}$, \\ Rejane H. Carvalho a, Maria T. Martinez-Larrad ${ }^{\mathrm{e}}$, \\ Elisabeth Coll Torres ${ }^{\mathrm{f}}$, Manuel Serrano-Rios ${ }^{\mathrm{e}}$ \\ ${ }^{a}$ Department of Medicine, Medical School, Federal University of Bahia, \\ Salvador-Bahia, Brazil \\ ${ }^{\mathrm{b}}$ Department of Medicine, Bahiana School of Medicine and Public Health, Bahia, Brazil \\ ${ }^{\mathrm{c}}$ Instituto de Saúde Coletiva, Federal University of Bahia, Brazil \\ ${ }^{\mathrm{d}}$ Department of Life Science, State University of Bahia, Brazil \\ ${ }^{\mathrm{e}}$ Department of Internal Medicine, Hospital Universitario de San Carlos, Madrid, Spain \\ ${ }^{\mathrm{f}}$ Department of Preventive Medicine, Hospital Universitario de San Carlos, Madrid, Spain
}

Received 2 May 2005; received in revised form 18 August 2005; accepted 1 September 2005

Available online 17 October 2005

\begin{abstract}
A cross-sectional study was performed involving epidemiological and clinical features of the metabolic syndrome (MS) in Spanish migrants to Brazil and their descendants. This included 479 subjects: Group A (Spanish migrants): $n=215$; Group B (descendants born in Brazil of Spanish parents): $n=126$, Group C (mixed descendants born in Brazil with either father or mother born in Spain): $n=138$. MS was defined according to the original NCEP/ATP III criteria and by the revised NCEP/ATP definition (glucose $\geq 100 \mathrm{mg} / \mathrm{dl}$ ). Overall prevalence of MS according to NCEP/ATP III criteria was $26.3 \%$. Age/sex-adjusted prevalence was $27.4 \%$. When the revised NCEP criteria were considered, overall prevalence was $30.1 \%$ (age/sex-adjusted $31.3 \%$ ). The differences between the two criteria were 3.8\% and 3.9\% (CI -1.9-9.4\%). When stratified by groups the MS was more prevalent in Group A (37.2\%) and Group B (20.6\%) than in Group C (10.9\%). Environmental factors may have influenced the development of MS. Reason for the apparently protective role of genetic features due to admixture between populations in the mixed descendants needs to be explored.
\end{abstract}

(C) 2005 Elsevier Ireland Ltd. All rights reserved.

Keywords: Metabolic syndrome; Migrants; Diabetes

\section{Introduction}

The prevalence of the metabolic syndrome and the pattern of disturbances associated with insulin resistance vary according to race and ethnicity [1-4].

\footnotetext{
* Corresponding author.

E-mail address: judicarreiro@terra.com.br (Judith M.D.C. Pousada).
}

The effect of migration on some components of their metabolic profile has been documented in different countries [5]. Variations in the prevalence of diabetes mellitus (DM) in migrants and their offspring in the new host country as compared to the natives in their own countries have been observed [6,7].

Although some traditional components are preserved, the dietary practices of the immigrant populations tend to change, assimilating nutrients, way of 
preparing foods and different life styles, which may result in an increase of overweight persons [8-10].

There are many studies about the environmental influence on the prevalence of diabetes and obesity in migrant populations $[7,11]$ but only a few reports focus the prevalence of metabolic syndrome in migrants and their descendants [12].

Spanish migration to Brazil occurred predominantly in the first half of the 20th century, especially to Bahia, a state located in the Northeast region of Brazil, whose capital is Salvador. Almost $96 \%$ of the migrants came from Galicia, the Northwestern corner of the Iberian Peninsula $[13,14]$. The migration was essentially due to underprivileged socio-economic conditions.

The aim of this study was to investigate the epidemiological and clinical features of the metabolic syndrome (MS) in Spanish migrants to Salvador, Brazil and in their descendants.

\section{Material and methods}

A cross-sectional study was conducted in Spanish migrants and their offspring in Salvador, Bahia, Brazil.

A total of 753 Spaniards and their descendants presently living in Salvador and registered with the Spanish Consulate or at the Spanish Hospital as members of Spanish community in Salvador, Brazil were invited by mail to participate in the study. Of this total, 180 deceased or returned to Spain. Of the remaining 573, $15(2.6 \%)$ refused and $79(13.8 \%)$ agreed to participate, but did not show up (26 in Spain for more than 6 months, $4.5 \%$ ) or had incomplete data (53 or $9.3 \%$ ). The total sample included 479 participants who were classified into three groups.

Group A: Spanish migrants having lived in Brazil for more than 30 years.

Group B: Descendants born in Brazil of Spanish parents.

Group $C$ : Mixed descendants born in Brazil with either father or mother born in Spain.

Of the 53 participants, 29 (11.9\%) would have been classified as Group A, 8 (6\%) as Group B and $16(10.4 \%)$ as Group C, not included due to incomplete data.

An interview was conducted, using a standard questionnaire. Questions included place of origin, family history of diabetes, smoking habit, dietary practices, physical activities and related diseases. The anthropometrical measurements were obtained in duplicate and consisted of weight, height and waist circumference measured at the level of umbilicus. BMI was computed as the ratio of weight $(\mathrm{kg})$ to the square of height $(\mathrm{m})\left(\mathrm{kg} / \mathrm{m}^{2}\right)$. Blood pressure was measured twice in a sitting position after a supine rest of $5 \mathrm{~min}$.

Biochemical determinations were done by a board certified laboratory and blood was collected after a 12-h fasting. The subjects were asked to abstain from smoking for $12 \mathrm{~h}$ and from consuming alcohol for 3 days before blood was drawn, and tests included: a fasting glucose determination using the glucose oxidase method, the coefficient of variation being $<10 \%$; the lipid profile comprising total cholesterol, triglycerides and HDL-c was measured using the enzyme colorimetric method and the LDL-c was calculated based on the Friedwald equation [15]. Serum insulin was measured by RIA (Human Insulin Specific RIA Kit, Linco Research Inc., St. Louis, MO, USA). Insulin resistance (IR) was estimated according to the homeostasis model assessment (HOMA-IR) method from fasting glucose and insulin concentrations, according to the formula: (insulin $(\mathrm{mU} / \mathrm{ml}) \times$ fasting plasma glucose $(\mathrm{mmol} / \mathrm{l})) / 22.5$ [16].

Insulin resistance was considered when HOMA $\geq 3.8$ [17]. MS was defined according to the Third Report of the National Cholesterol Education Program (NCEP) Expert Panel on Detection, Evaluation and Treatment of High Blood Cholesterol in Adults [18] where three or more of the following criteria should be present: (1) abdominal obesity: waist circumference $>102 \mathrm{~cm}$ in men and $>88 \mathrm{~cm}$ in women; (2) hypertriglyceridemia: $\geq 150 \mathrm{mg} / \mathrm{dl}(1.69 \mathrm{mmol} / \mathrm{L})$; (3) low HDL-c: $<40 \mathrm{mg} / \mathrm{dl}(1.04 \mathrm{mmol} / \mathrm{L})$ in men and $<50 \mathrm{mg} / \mathrm{dl}$ $(1.29 \mathrm{mmol} / \mathrm{L})$ in women; (4) high blood pressure: $\geq 130 /$ $\geq 85 \mathrm{mmg} \mathrm{Hg}$; (5) fasting plasma glucose (FPG) $\geq 110 \mathrm{mg} / \mathrm{dl}$ $(6.1 \mathrm{mmol} / \mathrm{L})$. Individuals on fibrates, on anti-hypertensive or anti-diabetic therapy were included in criteria 2, 4 and 5, respectively. Because of the revision of the glucose levels criterion of MS, the prevalence of MS is also reported, using a glucose cut-point of $\geq 100 \mathrm{mg} / \mathrm{dl}$ [19]. Impaired fasting glucose was considered when FBG levels $\geq 100 \mathrm{mg} / \mathrm{dl}$ but $<126 \mathrm{mg} / \mathrm{dl}$. Diabetes was considered when fasting plasma glucose $\geq 126 \mathrm{mg} / \mathrm{dl}$ [20].

A local institutional ethics committee approved the study protocol, and all subjects gave their written informed consent.

\subsection{Statistical methods}

Quantitative variables are shown by their mean and standard deviations (S.D.). Student's $t$-test and one-way ANOVA were used to scale variables. The categorical variables were described as proportions and compared by $\chi^{2}$-test. Logistic regression was used to evaluate the impact of age, sex and each component on the metabolic syndrome. Stratified analyses for interactions using cross-product terms-Pearson $\chi^{2}$ was performed including the metabolic syndrome, insulin resistance, smoking and physical activity. Significance was considered to be $p<0.05$. All analyses were done by using SPSS 10.0 software (SPSS Inc., Chicago, IL).

\section{Results}

The study included 479 subjects as follows- Group A: $n=215(68.4 \pm 10.6$ years, $60.9 \%$ men); Group B: $n=126$ (48.9 \pm 14.9 years, $39.7 \%$ men); and Group C: $n=138$ (40.2 \pm 16.5 years, $52.2 \%$ men). In mixed 
descendants, Group C, $91.2 \%$ born of Brazilian mothers.

The overall prevalence of the MS was $26.3 \%(95 \%$ CI $23.4-31.4)(29.6 \%$ in men and $22.6 \%$ in women: $p=0.08)$, and the age/sex-adjusted prevalence was 27.4\% (95\% CI 23.4-31.4). When the revised NCEP criteria were considered the overall prevalence was $30.1 \%$ (age/sex-adjusted 31.3\%). The difference between the two criteria was $3.8 \%$ and $3.9 \%$, respectively (95\% CI $-1.9-9.4 \%$ ).

When analyzed by groups, this prevalence was: Group $\mathrm{A}=37.2 \% \quad(95 \%$ CI $30.7-43.7)$. Group $\mathrm{B}=20.6 \%(95 \%$ CI $13.5-27.6)$ and Group $\mathrm{C}=10.9 \%$ (95\% CI 5.7-16.1).

Table 1 contains clinical and biochemical data of the three groups of patients. When the aged adjusted characteristics were compared (post hoc test) the results were: the comparison between Groups A and B showed statistically significant differences in the following parameters: waist, systolic blood pressure, BMI and HDLc; the comparison between Groups A and $\mathrm{C}$ showed the following differences-waist, systolic and diastolic blood pressure, triglycerides and BMI; the comparison between Groups B and C showed differences only in BMI. These differences were more relevant between Group A and the two other.

The unadjusted and the age/sex-adjusted prevalence of MS by groups both using NCEP original criteria and the new glucose cut-points are shown in Fig. 1. For each of the groups, the difference between the prevalence of MS, both adjusted and unadjusted for age/sex, by using the original NCEP criteria and revised criterion, were minimal and not significant.

When the analysis was stratified in the individuals aged 50 and older $(n=305)$, the overall prevalence of metabolic syndrome was $35.6 \%$, and this prevalence remained higher for Groups A (37.9\% of 206) and B (37.5\% of 96$)$ than for $\mathrm{C}(18.2 \%$ of 33$)$.

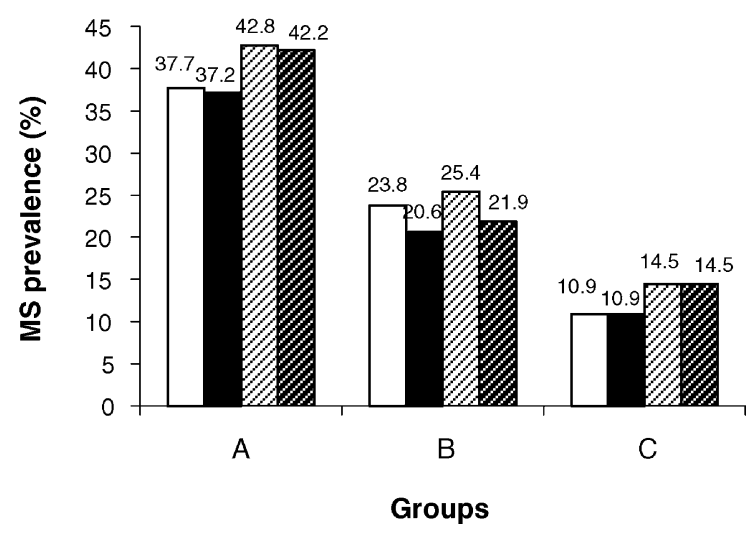

Fig. 1. Unadjusted and age/sex-adjusted prevalence of metabolic syndrome by groups: original and revised NCEP/ATP III definitions. ( $\square$ ) Unadjusted prevalence NCEP original criterion (A vs. B vs. C; $p<0.005$ ). ( $\square$ ) Age/sex-adjusted prevalence NCEP original criterion (A vs. B vs. C; $p<0.005$ ). (《) Unadjusted prevalence NCEP revised criterion (A vs. B vs. C; $p<0.005$ ). (Z) Age/sex-adjusted prevalence NCEP revised criterion (A vs. B vs. C; $p<0.005$ ).

Prevalence of risk factor components of the metabolic syndrome was different among groups, except for HDL cholesterol, similar in all three groups (Table 2).

The overall prevalence of obesity was $21.3 \%$. The prevalence by group was $31.4 \%$ in Group A, $15.1 \%$ in Group B and $11.6 \%$ in Group C.

The prevalence of smoking was similar in patients with and without MS: $6.3 \%$ (95\% CI 2.1-10.5) versus $8.5 \%$ (95\% CI 5.6-11.4), $p>0.05$.

The physical activity was more frequent in individuals without MS (48.7\%) than in those with $(36.3 \%), p=0.02$. However, after stratified analyses by groups, the statistical significance disappeared (Group $\mathrm{A}, p=0.15$; Group B, $p=0.45$; Group C, $p=0.30$ ).

The logistic regression analysis showed a significant positive association of waist circumference with MS (OR: 48.7; 95\% CI 21.0-113.6, $p=0.005$ ).

Table 1

Age adjusted characteristics in Spanish migrants to Brazil and their descendants: comparison between the three groups

\begin{tabular}{|c|c|c|c|c|}
\hline & Group A & Group B & Group C & $p$-Value \\
\hline BMI $\left(\mathrm{kg} / \mathrm{m}^{2}\right)$ & $28.6 \pm 4.4$ & $26.6 \pm 5.3$ & $25.8 \pm 4.5$ & 0.002 \\
\hline Waist $(\mathrm{cm})$ & $92.7 \pm 12.1$ & $86.0 \pm 13.4$ & $88.8 \pm 15.5$ & 0.009 \\
\hline Systolic BP & 130. \pm 18 & $122 \pm 16$ & $130 \pm 22$ & 0.032 \\
\hline Diastolic BP & $79 \pm 11$ & $78 \pm 12$ & $78 \pm 16$ & 0.800 \\
\hline Triglycerides $(\mathrm{mg} / \mathrm{dl})$ & $175 \pm 102$ & $134 \pm 79$ & $147 \pm 75$ & 0.022 \\
\hline HDLc (mg/dl) & $48 \pm 12$ & $54 \pm 14$ & $50 \pm 13$ & 0.024 \\
\hline Glycemia & $103 \pm 35$ & $93 \pm 17$ & $89 \pm 12$ & 0.009 \\
\hline Insulin & $18.4 \pm 8.8$ & $17.7 \pm 10.1$ & $18.5 \pm 9.0$ & 0.72 \\
\hline HOMA & $4.88 \pm 0.23$ & $4.25 \pm 0.27$ & $4.03 \pm 0.19$ & 0.02 \\
\hline
\end{tabular}


Table 2

Metabolic syndrome risk factors by groups

\begin{tabular}{llllr}
\hline Risk factor & $\begin{array}{l}\text { Group } \\
\text { A }(\%)\end{array}$ & $\begin{array}{l}\text { Group } \\
\text { B }(\%)\end{array}$ & $\begin{array}{l}\text { Group } \\
\text { C }(\%)\end{array}$ & $p$-Value \\
\hline Waist $>102 / 88 \mathrm{~cm}$ & 34.9 & 22.8 & 15.7 & $<0.001$ \\
Triglycerides $\geq$ & 46.0 & 32.3 & 29.1 & 0.002 \\
$\quad 150 \mathrm{mg} / \mathrm{dl}$ & & & & \\
HDL-cholesterol $<$ & 37.9 & 29.9 & 33.1 & 0.29 \\
$\quad 40 / 50 \mathrm{mg} / \mathrm{dl}$ & & & & \\
BP $\geq 130 / \geq 85 \mathrm{mmHg}^{\mathrm{a}}$ & 70.1 & 38.3 & 27.7 & $<0.001$ \\
Fasting glycemia $\geq$ & 24.1 & 10.2 & 2.8 & $<0.001$ \\
$\quad 110 \mathrm{mg} / \mathrm{dl}^{\mathrm{a}}$ & & & & \\
\hline
\end{tabular}

${ }^{\mathrm{a}}$ Includes treatments for the condition.

When taking into consideration the presence of MS, $85.1 \%$ in Spanish migrants, $78.6 \%$ in Spanish descendants and $75 \%$ in mixed descendants have insulin resistance $(p=0.57)$, that is, no significant differences are observed.

\section{Discussion}

The present study examined the prevalence of the metabolic syndrome in migrant populations. A lack of uniformity in the definition of universally accepted criteria and cut off points of diagnostic standards of the MS still limits its study, but the use of an established concept is helpful [21]. The NCEP definition followed in this paper uses clinical criteria and does not emphasize any metabolic parameter. But what it loses in sensitivity is compensated by its feasibility and specificity $[18,22]$.

The results showed that the prevalence of MS was 3.5 times higher in migrants and 2.2 higher in the Spanish descendants than in mixed descendants. Comparing the prevalence found in this study to that of Spanish individuals living in Spain $(21.7 \%)$ [4], the prevalence ratio was greater (1.71) for Group A, slightly lower (0.95) for Group B and considerably lower (0.50) for Group C. The age- and sex-adjusted prevalence of the metabolic syndrome using NCEP criteria in Salvador, Bahia, Brazil, was $15.5 \%$ [23]. When the new serum glucose cut-point was used, the prevalence of MS was practically the same to NCEP criteria.

The overall prevalence of MS, after age and sex adjustment $(27.4 \%)$, was similar to that reported in other countries, such as $27.0 \%$ in USA [24], $24.4 \%$ in Canary Islands [25] and 23\% in Colombia [26]. The detected prevalence of $35.6 \%$ in people over the age of 50 years was shown to be lower than that of 43.5\% found in American individuals at the same ages [27].
The analysis of HOMA in the context of MS showed that prevalence of MS was lower in mixed descendants, irrespective of insulin resistance. There is probably another protecting factor for this group. On the other hand, insulin resistance was equally present in all groups when stratified by MS. This observation suggests that insulin resistance may either progress to MS, or not.

The prevalence comparison for common risk factors of metabolic syndrome among the three groups showed that, except for HDL-c, which was similarly diminished in around one-third of the subjects in all three groups, all the other risk factors observed in Table 1 progressively diminished from Group A to Groups B and C. While Spanish migrants and their descendants (Group B), more frequently had central distribution of their adiposity, only $15.7 \%$ of mixed descendants, Group C, had a significant abdominal deposition of fat, which could have protected them from MS [28].

There is little mention of MS in migrants [12]. For this reason, there may be difficulty in comparing the present study data. On the other hand, there are many studies about diabetes in migrants [5-7].

In Spain the prevalence of obesity is $13.4 \%$ in women and $11.5 \%$ in men [29]. Among Spanish migrants the prevalence was higher than in their descendants. An explanation for the differences between the risk factors of MS in migrants and their pure descendants, and in the ethnically mixed migrant descendants born and raised in Bahia has not been established so far. It is possible that behavioral changes and environmental factors contributed significantly to the observed situation, but the influence of racial admixture cannot be ruled out.

Spanish migrants, exposed to an unfavorable nutritional environment due to financial difficulties [13], both in Spain and still more so during the first years of migration [14], probably amplified their preexistent insulin resistance. When in the following prosperous years they became jewelers, bakers, food supplies and building ware owners, dealers, hotel business, they were exposed to abundance of food and MS had a fertile terrain to become intensified. Children of Spanish parents exposed to an insulin-resistant uterine environment probably continued to have more tendency to develop the MS.

In mixed descendants, more than $90 \%$ born of Brazilian mothers [14], lack of intra-uterine predisposition, genetic admixture or a different life style (healthier food ingestion, and increased physical activity) could have attenuated the metabolic picture. 
The relative importance of the contribution of genetic and environmental factors in the changes observed generation after generation still await further clarification, but both nature and nurture surely interfere.

\section{Acknowledgments}

The authors wish to express special thanks to the Spanish Consulate and to the Spanish Hospital in Salvador, Bahia. This study was supported in part by $\mathrm{CNPq}$ (the Brazilian National Council for Technologic and Scientific Development), Bayer do Brazil, Aventis Pharma do Brasil and Servier do Brasil Ltda, Red de Centros RCMN (C03/08) Madrid, Spain. A part of this study was previously published in abstract form and presented at the 18th IDF Congress in Paris, France, 2003.

\section{References}

[1] P.Z. Zimmet, Kelly West Lecture 1991, Challenges in diabetes epidemiology-from west to the rest. Mauritius Non-Communicable Disease Study Group, Diabetes Care 15 (1992) 232-252.

[2] P.M. McKeigue, Ethnic variations in insulin resistance and risk of type 2 diabetes, in: G.M. Reaven, A. Laws (Eds.), Contemporary Endocrinology Insulin Resistance: The Metabolic Syndrome X, Human Press Inc., Totowa, USA, 1999, pp. 19-33.

[3] E.S. Ford, W.H. Giles, W.H. Dietz, Prevalence of the metabolic syndrome among US adults. Findings from the third NHANES, JAMA 287 (2002) 356-359.

[4] M.T. Martinez-Larrad, J.L. Gonzalez-Sanchez, C. FernandezPerez, R. Gabriel, J.A. Gomez-Gerique, M. Serrano-Rios, Prevalence of the metabolic syndrome in a population sample from Spain (Abstract), Diabetes 52 (Suppl 1) (2003) A502.

[5] T. Valle, J. Tuomilehto, J. Eriksson, Epidemiology of NIDDM, in Europids, in: K.G.M.M. Alberti, P. Zimmet, R.A. DeFronzo, H. Keen (Eds.), International Textbook of Diabetes Mellitus, second ed., John Wiley and Sons, Baffin Lanes, Chichester, England, 1997, pp. 125-140.

[6] M.G. Marmot, S.L. Syme, A. Kagan, H. Kato, J.B. Cohen, J. Belsky, Epidemiologic studies of coronary heart disease and stroke in Japanese men living in Japan Hawaii and California, Am. J. Epidemiol. 102 (1975) 514-525.

[7] S.G.A. Gimeno, S.R.G. Ferreira, L.J. Franco, A.T. Hirai, L. Matsunura, R.S. Moises, Prevalence and 7 year incidence of type II diabetes mellitus in a Japanese-Brazilian population: an alarming public health problem, Diabetologia 45 (2002) $1635-1638$.

[8] L.J. Franco, Diabetes in Japanese Brazilians-influence of the acculturation process, Diabetes Res. Clin. Pract. 34 (Suppl.) (1996) S51-S57.

[9] DECODE Study Group, Age, body mass index and type 2 diabetes-associations modified by ethnicity, Diabetologia 46 (2003) 1063-1070.

[10] P.M. McKeigue, Metabolic consequences of obesity and body fat pattern: lesson from migrant studies, Ciba Found Symp. 201 (54-64) (1996) 188-193 (Discussion 64-67).
[11] A.M. Hodge, D.R. English, K. O’Dea, G.G. Graham, Increased diabetes incidence in Greek and Italian migrants to Australia. How much can be explained by known risk factors? Diabetes Care 27 (2004) 2330-2334.

[12] D.D.G. Lerario, S.G. Gimeno, L.J. Franco, M. Iunes, S.R.G. Ferreira, Weight excess and abdominal fat in the metabolic syndrome among Japanese-Brazilians, Rev. Saude Publica 36 (2002) 4-11.

[13] Xunta de Galicia, Galicia e América-Cinco Siglos de Historia, Consello de Cultura Gallega, Xunta de Galicia, 1993.

[14] C.M.L. Braga, Memórias de Imigrantes Galegos. Salvador, Ba, Universidade Federal da Bahia, Centro Editorial e Didático da UFBa, 1995.

[15] W.T. Friedwald, R.I. Levy, D.S. Friedrickson, Estimation of the concentration of low-density lipoprotein cholesterol in plasma, without the use of the preparative ultracentrifugate, Clin. Chem. 18 (1972) 499-502.

[16] D.R. Mathews, J.P. Hosker, A.S. Rudenski, B.A. Naylor, D.F. Treacher, R.C. Turner, Homeostasis model assessment: insulin resistance and $\beta$-cell function from fasting plasma glucose and insulin concentrations in man, Diabetologia 28 (1985) 412419.

[17] J.F. Ascaso, P. Romero, J.T. Real, A. Priego, C. Valldecabres, R. Carmena, Insulin resistance quantification by fasting insulin plasma values and HOMA index in non-diabetic subjects, Med. Clin. (Barna) 117 (2001) 530-533.

[18] Expert Panel on Detection, Evaluation and Treatment of High Blood Cholesterol in Adults: Executive Summary of the Third Report of the National Cholesterol Education Program (NCEP) Expert Panel on Detection, Evaluation and Treatment of High Blood Cholesterol in Adults (Adult Treatment Panel III), JAMA 285 (2001) 2486-2497.

[19] S.M. Grundy, H.B. Brewer Jr., J.L. Cleman, S.C. Smith Jr., C. Lenfant, Definition of metabolic syndrome: report of the National Heart, Lung, and Blood Institute/American Heart Association Conference on scientific issues related to definition, Circulation 109 (2004) 433-438.

[20] American Diabetes Association, Standards of medical care in diabetes, Diabetes Care 28 (Suppl. 1) (2005) 4-36.

[21] EGIR-The European Group for the Study of Insulin Resistance, Frequency of the WHO syndrome in European cohorts, and an alternative definition of an insulin resistance syndrome, Diabetes Metab. 28 (2002) 364-376.

[22] G.B. Meigs, Metabolic syndrome. In search of a clinical role, Diabetes Care 27 (2004) 2761-2763.

[23] P.T.B. Barbosa, I. Lessa, Critério de obesidade central em uma população brasileira: impacto sobre a síndrome metabólica. In: Barbosa, PSBB. Epidemiologia da Síndrome Metabólica numa população urbana brasileira. Tese de Doutorado, Instituto de Saúde Coletiva, Universidade Federal da Bahia, Salvador, Bahia, Brasil, 2005, $115 \mathrm{pp}$.

[24] E.S. Ford, W.G. Giles, A.H. Mokdad, Increasing prevalence of the metabolic syndrome among US Adults, Diabetes Care 27 (2004) 2444-2449.

[25] E.E. Alvarez Leon, L. Ribas Barba, L. Serra Majem, Prevalencia del síndrome metabólico en la población de la Comunidad Canaria, Med. Clin. (Barc) 120 (2003) 172-174.

[26] A. Villegas, J.F. Botero, I.C. Arango, S. Arias, M.M. Toro, Prevalencia del síndrome metabólico en El Retiro, Colombia, Rev. Assoc. Latinoam Diab. 12 (2004) 20-24.

[27] C.M. Alexander, P.B. Landsman, S.M. Tevisch, S.M. Haffner, NCEP-defined metabolic syndrome, diabetes, and 
prevalence of coronary heart disease among NHANES III participants age 50 years and older, Diabetes 52 (2003) 1210 1214.

[28] C. Lorenzo, M. Serrano-Rios, M.T. Martinez-Larrad, R. Gabriel, K. Willams, J. Gómez-Gerique, et al. Central adiposity determines prevalence differences of the metabolic syndrome, Obes. Res. 14 (2003) 1480-1487.

[29] J. Aranceta, C.P. Rodrigo, L.S. Majem, L. Ribas, J.Q. Izquierdo, J. Vioque, et al. Prevalencia de la obesidad en España: estudio SEEDO'97, Med. Clin. (Barc) 111 (1998) 441-445. 